\title{
UMA EXPERIÊNCIA DE INCLUSÃO DE ALUNAS CEGAS DO CURSO DE LICENCIATURA EM FÍSICA DO IFRN NA DISCIPLINA DE CÁLCULO DE FUNÇÕES DE UMA VARIÁVEL
}

\section{UNA EXPERIENCIA DE INCLUSIÓN DE ESTUDIANTES CIEGOS EN EL CURSO DE LICENCIA FÍSICA DE IFRN EN EL CÁLCULO DE FUNCIONES DE UNA VARIABLE}

\section{AN EXPERIENCE OF INCLUSION OF BLIND STUDENTS OF PHYSICS COURSE FROM IFRN IN THE SUBJECT OF CALCULATION OF FUNCTIONS OF ONE VARIABLE}

\begin{abstract}
Rita de Cássia Paulo dos Santos ${ }^{1}$; Wellington Muniz de Souza ${ }^{2}$; Caio Vasconcelos Pinheiro da Costa ${ }^{3}$; Tácio Vitaliano da Silva ${ }^{4}$; Rainelly Cunha de Medeiros ${ }^{5}$
\end{abstract}

DOI: https://doi.org/10.31692/978-65-991061-3-2.163-168

\section{INTRODUÇÃO}

No Brasil, o aumento do número de matrículas de pessoas com deficiência no ensino superior consiste de um movimento atual, resultado de políticas públicas recentes. Esse movimento, porém, não parece ter vindo acompanhado de ações de incentivo à formação docente no tocante às necessidades pedagógicas específicas desse público alvo. Quando se fala em alunos cegos cursando a disciplina de "Cálculo de funções de uma variável”, por exemplo, é comum, inclusive entre professores da área de Matemática, perceber um certo espanto que vem acompanhado da pergunta: como ensinar tais conteúdos para esses alunos? Diante da frágil formação inicial docente e da ausência de uma melhor compreensão sobre as particularidades de cada deficiência, torna-se ainda mais difícil avançar na direção da educação inclusiva.

Segundo Haddad e Sampaio (2010), estima-se que há aproximadamente 4 milhões de indivíduos com baixa visão e 1,2 milhões de cegos no Brasil. A Lei Brasileira de Inclusão - lei no 13.146, de 6 de julho de 2015 - incube ao poder público assegurar-lhes o acesso à educação superior e à educação profissional e tecnológica em igualdade de oportunidades e condições com as demais pessoas. No entanto, o direito de acesso a esses níveis de ensino, por si só, não assegura a compreensão do conteúdo abordado, uma vez que isso requer posturas inclusivas por parte de docentes e colegas. Muitas vezes, barreiras atitudinais e de comunicação tornam o tempo em sala de aula improdutivo para o estudante com deficiência, que parece invisível aos olhos dos que o cercam, talvez pelo "medo" do desconhecido e/ou pelo entendimento

\footnotetext{
${ }^{1}$ Licenciatura em Física, IFRN, e-mail: ritinhahesed@hotmail.com

${ }^{2}$ Licenciatura em Matemática, IFRN, e-mail: wallenmuniz@yahoo.com.br

${ }^{3}$ Mestre em Ciências Climáticas, IFRN, e-mail: caio.vasconcelos@ifrn.edu.br

${ }^{4}$ Doutor em Educação, IFRN, e-mail: taciovsilva@yahoo.com.br

${ }^{5}$ Doutora em Matemática, IFRN, e-mail: rainelly.cunha@ifrn.edu.br
} 
equivocado de que a pessoa com deficiência deve ser tratada como os demais e buscar a sua própria adaptação (FREITAS, FOSSATTI, KORTMANN; 2017). Diante disso, a questão passa a ser agora a inclusão e a permanência desses estudantes nos cursos superiores.

Este trabalho apresenta uma situação de inclusão de duas estudantes cegas do curso superior de Licenciatura em Física do IFRN - campus Natal Central - no desafiador processo de aprendizagem dos conteúdos da disciplina "Cálculo de funções de uma variável”. Esta pesquisa consiste em um relato de experiência coligado à pesquisa-ação e tem por objetivo oportunizar apropriação do conhecimento pelas alunas, bem como compreender os desafios que acompanham a atividade docente na inclusão de pessoas com necessidades educacionais específicas. Ao longo do acompanhamento dessas estudantes, verificou-se a possibilidade de confecção de materiais táteis de baixo custo, incluindo a transcrição em alto relevo de conceitos e regras algébricas para apropriação dos conteúdos da disciplina pelas educandas, com uso dentro e fora da sala de aula.

Pouco se tem documentado sobre a inclusão de pessoas com deficiência no Ensino Superior, indicando uma carência de reflexões e propostas pedagógicas para esse nível de ensino. Freitas et al. (2017) ressaltam a importância de trabalhos como esse:

\footnotetext{
Relatos de uma acessibilidade plena, educação inclusiva, ainda são pontuais, mas devem ser valorizados e servir de exemplo para multiplicação e consolidação do direito ao ensino em todos os níveis e ao longo de toda a vida para todas as pessoas, conforme preconiza a Lei Brasileira da Inclusão.
}

\section{FUNDAMENTAÇÃO TEÓRICA}

De acordo com o Projeto Político Pedagógico do IFRN, o movimento mundial pela inclusão constitui-se em uma ação de caráter político, social e histórico que reconhece e valoriza a diversidade como condição indispensável à constituição de qualquer sociedade. O documento ainda acrescenta que a educação inclusiva se origina nesse contexto, remetendo a uma ação que instaura um nível de importância ao direito de todos à educação. Nesse sentido, deve-se propiciar escolas abertas a todos, em qualquer etapa ou modalidade, e acesso a níveis mais elevados de ensino. Entende-se a inclusão indo além dos limites da deficiência, estendendo-se todos os sujeitos tratados, nos debates das políticas públicas, como "minorias" ou "excluídos". Essa concepção sustenta práticas pedagógicas que, “em vez de pressupor que o aluno deva ajustar-se aos padrões de 'normalidade' para aprender, apontam para a escola o desafio de ajustar-se para atender a diversidade de seus alunos". (BRASIL, 2001b, p. 15).

Não é tarefa fácil incluir o estudante com deficiência em sala de aula. O processo de 
inclusão passa pelo entendimento das particularidades de cada caso. A deficiência visual, que é caracterizada pela limitação ou perda das funções básicas do olho e do sistema visual, por exemplo, requer estratégias metodológicas muito diferentes daquelas que são necessárias a alunos com problemas auditivos.

Sá, Campos e Silva (2007) afirmam que o sistema visual detecta e integra de forma instantânea e imediata cerca de $80 \%$ dos estímulos do ambiente, isso mostra a dependência do ser humano perante a visão. No entanto, segundo os autores, a falta da visão não interfere na capacidade intelectual e cognitiva. Estudantes com deficiência visual têm o mesmo potencial de aprendizagem e podem demonstrar um desempenho escolar equivalente ou superior ao de alunos que enxergam mediante condições e recursos adequados. Os autores ainda destacam que eles podem ser mais lentos na realização de algumas atividades, pois a dimensão analítica da percepção tátil demanda mais tempo, e que precisam manipular e explorar o objeto para conhecer as suas características e fazer uma análise detalhada das partes para tirar conclusões. Essa diferença básica é importante porque influi na elaboração de conceitos e interiorização do conhecimento. É natural, portanto, que as estratégias e situações de aprendizagem para com eles valorizem a estimulação do tato, principalmente.

\section{METODOLOGIA}

Participam desta pesquisa duas alunas com deficiência visual regularmente matriculadas no curso superior de licenciatura em Física do Instituto Federal de Educação, Ciência e Tecnologia do Rio Grande do Norte - IFRN. Elas assistem aula de cálculo em uma turma com 36 alunos, nas segundas e quartas-feiras, no horário vespertino e tem atendimento individualizado no contra turno nas terças e quintas-feiras.

Esta pesquisa é de natureza quantitativa e qualitativa, uma vez que foram considerados aspectos subjetivos, como os depoimentos das alunas participantes e de seus colegas de turma, mas, também, aspectos quantificáveis como o rendimento das alunas nas provas da disciplina. Também pode ser classificada, quanto ao tipo, como um relato de experiência, porém, com algumas características de uma pesquisa-ação, pois, além de expor experiências vivenciadas numa situação específica, os pesquisadores tiveram influência no desenvolvimento e nos resultados obtidos. Para a aquisição dos dados foram utilizados como instrumentos as provas escritas aplicadas na disciplina (porém, de maneira adaptada, tendo em vista as necessidades das alunas), bem como os depoimentos destas e de seus colegas de turma.

Antes de passar a descrição dos procedimentos utilizados, é importante ressaltar que ambas as participantes da pesquisa têm cegueira adquirida, sendo que perderam completamente 
a visão durante a fase da adolescência, de forma que ambas são alfabetizadas, o que foi fundamental para o êxito das intervenções realizadas. Além disso, apenas uma das estudantes consegue ler e escrever em Braille, sistema de leitura com o tato, inventado pelo francês Louis Braille no ano de 1827. Assim, nas intervenções em que as duas discentes estavam presentes, só foi possível a utilização dos recursos táteis e auditivos para se trabalhar os conteúdos. Em alguns momentos, quando apenas a aluna alfabetizada em Braille esteve presente, foi possível ensiná-la alguns símbolos matemáticos específicos do Cálculo Diferencial e Integral para que ela pudesse fazer as suas próprias anotações, tática que, segundo a própria aprendiz, conduzia a uma apropriação mais rápida dos conteúdos.

As intervenções foram realizadas em sala de aula, às segundas e quartas-feiras à tarde, e em horários de atendimento particulares no contraturno. Nas duas ocasiões, os principais conceitos eram apresentados por meio de materiais táteis e em alto-relevo, contudo, nos atendimentos particulares, em geral, eram resolvidos mais exercícios juntamente às alunas. Foram realizadas algumas tentativas de utilização de diferentes materiais táteis como, por exemplo: representações geométricas feitas em papel de $120 \mathrm{~g} / \mathrm{m}^{2}$, produzidas através do desenho espelhado, estando o papel sobreposto a uma camada de EVA (Método 1), ou utilizando cola alto-relevo (Método 2); e propriedades algébricas escritas com cola quente em papel ou cartolina (Método 3).

As provas e listas de exercícios foram produzidas em via escrita, utilizando-se o Método 1, por ser um método mais acessível financeiramente e mais prático, quando a disponibilidade de tempo para a produção é reduzida. As avaliações escritas foram aplicadas em datas diferentes, para cada discente, a fim de que uma não pudesse ter acesso às respostas da outra. As alunas realizaram a leitura das questões, por meio do tato e diante da dificuldade de escrita observada, a professora efetuou a transcrição das respostas narradas por elas.

\section{RESULTADOS E DISCUSSÕES}

Os dados analisados referentes aos encontros com as alunas com deficiência visual apontam para uma aprendizagem significativa em relação aos conceitos e propriedades dos Limites. O rendimento na prova escrita, que tratou do referido conteúdo, foi de mais de $85 \%$ para ambas, resultado que, ao ser comparado ao dos estudantes sem nenhuma limitação, evidencia que "a escolarização e educação da pessoa cega ou com baixa visão é de modo geral viável em todos os níveis, desde que lhe sejam oferecidos os meios necessários para o desenvolvimento de sua autonomia e independência." (ORRICO, CANEJO E FOGLI, 2009, p. 121). Todavia, também foram observadas dificuldades por parte das discentes com deficiência 
em relação a conhecimentos básicos necessários à resolução das questões abordadas como: produtos notáveis, fatoração e equação do $2^{\circ}$ grau. Essas dificuldades se devem a lacunas na formação adquirida no Ensino Básico e ocasionaram problemas para a resolução de limites envolvendo indeterminações.

Foi constatado, dentre os métodos de produção de material avaliados, que aquele que melhor se adequou à dinâmica do dia-a-dia, levando em conta o contexto de pouco tempo disponível por parte da professora da disciplina, foi o Método 1. Um fator que contribuiu para o sucesso desse método foi que a docente já tinha a habilidade de escrever de maneira espelhada, das suas vivências anteriores. Além disso, ela também contou com o apoio de um professor visitante e de um orientando para auxiliá-la nas intervenções em sala de aula e nos momentos de atendimento individualizado.

Também foi verificado que a habilidade dos docentes e alunos (professores em formação) envolvidos com esse processo foi bastante desenvolvida, o que pode ser de grande valia caso ocorram experiências futuras com estudantes que tenham características semelhantes.

\section{CONCLUSÕES}

Com essa experiência, foi possível observar o quanto os cursos de formação de professores (licenciaturas) ainda possuem lacunas do que diz respeito à questão da inclusão. Em geral, nesses cursos, os estudantes não vivenciam experiências com alunos cegos, surdos ou com outro tipo de deficiência, de forma que tendem a apresentar dificuldades em lidar com esse público quando ocorrem situações como a descrita neste trabalho.

No entanto, existindo responsabilidade e interesse em incluir alunos com necessidades educacionais específicas, apesar das lacunas existentes na formação dos docentes, é possível encontrar estratégias que reduzam as dificuldades no seu processo de ensino-aprendizagem. Nesse sentido, desejamos que a inclusão destes seja uma prática incentivada e mais frequente no ambiente escolar.

Além disso, ficou evidente a necessidade de mais de um professor atuando nas turmas em que existem alunos com deficiência. Apesar de, em nosso caso, a deficiência das discentes ser visual, fica claro que esta necessidade se estende também a outras situações.

Por fim, esperamos que o aprendizado relatado neste trabalho em relação aos métodos de produção de material didático e estratégias de ensino para alunos cegos possam servir como ponto de partida para outros profissionais, no processo de inclusão de estudantes com características similares. 


\section{REFERÊNCIAS}

BRASIL, Lei n. 13.005, de 25 de junho de 2014. Aprova o Plano Nacional de Educação - PNE e dá outras providências. 2014. Diário Oficial da República Federativa do Brasil, Brasília, DF, n. 120, p. 1, 26 jun. 2014. Seção 1. Edição Extra.

BRASIL. Ministério da Educação. Parecer CNE/CEB n. 17/2001. Diretrizes Nacionais para a Educação Especial na Educação Básica. Diário Oficial da República Federativa do Brasil, Brasília, DF, n. 158, p. 46.17 ago. 2001. Seção 1.

DUARTE, E. R. et al. Estudo de caso sobre a inclusão de alunos com deficiência no ensino superior. Revista Brasileira de Educação Especial [online], v. 19, n. 2, 2013. Disponível em: http://www.scielo.br/scielo.php?script=sci_arttext\&pid=S1413-65382013000200011. Acesso em: 19 out. 2019.

FREITAS, S. V. D. H.; FOSSATTI, P.; KORTMANN, G. M. L. Inclusão de pessoas com deficiência (PCD) na educação superior: um olhar a partir das políticas de inclusão. In: GIANEZINI, Kelly; GROSS, Jacson (Org.). Estudos contemporâneos em ciências jurídicas e sociais. Florianópolis: Dois Por Quatro; Criciúma, SC: UNESC, 2017. p. 79-97. DOI: 10.18616/cienciasjuridicas04.

ORRICO, H. CANEJO, E. FOGLI, B. Uma reflexão sobre o cotidiano escolar de alunos com deficiência visual em classes regulares. In: GLAT, Rosana. Educação Inclusiva: cultura e cotidiano escolar. Rio de Janeiro: 7 Letras, 2009. p.116-136.

SÁ, E. D. de; CAMPOS, I.M.; SILVA, M.B.C. Atendimento Educacional Especializado Deficiência visual. Brasília: Ministério da educação, 2007. Disponível em:

http://portal.mec.gov.br/seesp/arquivos/pdf/aee_dv.pdf. Acesso em 18 out. 2019. 